\title{
INFLUÊNCIA DO PROCESSO DE TRANSFORMAÇÃO NA GERAÇÃO DE ACETALDEÍDO E NÍVEIS RESIDUAIS EM EMBALAGENS DE POLI (ETILENO TEREFTALATO) (PET) E EM BEBIDAS \\ - ARTIGO DE REVISÃO -
}

INFLUENCE OF THE PROCESS IN THE GENERATION OF ACETALDEHYDE AND RESIDUAL LEVELS IN POLY (ETHYLENE TEREPHTHALATE) (PET) PACKAGING AND DRINKS

- REVIEW ARTICLE -

\begin{abstract}
CARLOS ALBERTO RODRIGUES ANJOS 1
\end{abstract}
\section{RESUMO}

O principal objetivo deste texto é reunir informações relativas à presença do composto acetaldeído, sua formação, reações químicas, formas pelas quais se manifesta em bebidas e fontes de contaminação provenientes de diferentes caminhos nos sistemas de produção, embalagem e ambiente. Trata-se de um trabalho de revisão bibliográfica comentada e discutida, onde o autor insere sua experiência em tecnologia de transformação de resinas de PET, bem como embalagens para diversos produtos acondicionados e também fundamentos teóricos e práticos das etapas do processo relacionadas à formação de acetaldeído.

Palavras-chaves: Embalagem, Bebidas, Poli (etileno tereftalato).

\footnotetext{
${ }^{1}$ Prof. Dr. DTA - FEA - UNICAMP - Cidade Universitária Zeferino Vaz - Campinas, SP. anjos@reitoria.unicamp.br
} 


\begin{abstract}
The main objective of this text is to congregate relative information to the presence of the acetaldehyde, its chemical formation, reactions, forms for which if manifest in drinks and sources of contamination proceeding from different ways in the production systems, packaging and environment. It is a review of commented and discussed references, where the author inserts its experience in technology of PET resin transformation, as well as packaging for diverse conditioned products and also theoretical and practical beddings of the related stages of the process to the acetaldehyde formation.
\end{abstract}

Keywords: packaging, drinks, poly (ethylene terephthalate)

\title{
INTRODUÇÃO
}

Os sabores e aromas de bebidas em geral podem ser alterados pela presença de acetaldeído, seja proveniente do ambiente, do próprio produto e/ou do material de embalagem utilizado. Do ponto de vista de contaminação advinda do ambiente, as fontes podem ser diversas, tais como: combustão de madeira, torração de café, fabricação de ácido acético e acetato de vinila a partir de etileno, dentre outras. A síntese ou formação no próprio alimento provém, também, de diferentes vias, principalmente pela oxidação primária do etanol ou álcool etílico e dos processos de fermentação para a produção de alimentos e bebidas.

O acetaldeído é um líquido volátil, incolor e de odor pungente. É miscível em água e em diversos solventes, sendo que em concentrações diluídas apresenta aroma de fruta cítrica. Os sinônimos mais comuns do acetaldeído são etanol, aldeído acético, acetilaldeído, etilaldeído, dietilacetal e 1,1 dietioxi-etano, cuja estrutura molecular é mostrada na Figura 1.

$$
\mathrm{H}_{3} \mathrm{C}-\mathrm{C} \geqslant \frac{\mathrm{O}}{\mathrm{H}}
$$

Figura 1. Fórmula estrutural do acetaldeído

Conforme descrito por TAYLOR (1986), o acetaldeído é um produto originado da oxidação do álcool etílico e está presente em diversos alimentos acondicionados, águas e bebidas em geral. Entretanto, determinados níveis desse composto em alimentos pode ser indicativo da ocorrência de termo degradação do polímero durante a fabricação da embalagem ou devido à alteração de sabor e aroma dos produtos pela composição química, podendo comprometer a estabilidade dos mesmos.

O acetaldeído é produzido comercialmente através da oxidação do álcool etílico ou pela hidratação do acetileno. As Figuras 2 e 3 mostram as reações de obtenção do acetaldeído através da oxidação do álcool etílico e da hidratação do acetileno, respectivamente.

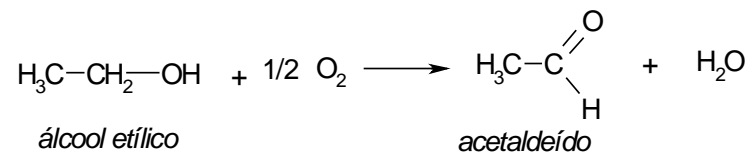

Figura 2. Obtenção do acetaldeído através da oxidação do álcool etílico.

$$
\begin{aligned}
& 2 \mathrm{HC} \equiv \mathrm{CH}+2 \mathrm{H}_{2} \mathrm{O} \longrightarrow 2 \mathrm{H}_{3} \mathrm{C}-\mathrm{C}_{\backslash}^{\prime /}+1 / 2 \mathrm{O}_{2} \\
& \text { acetileno acetaldeído }{ }^{\mathrm{H}}
\end{aligned}
$$

Figura 3. Obtenção do acetaldeído através da hidratação do acetileno.

O acetaldeído é um composto de ocorrência natural, aparecendo em frutas maduras que apresentam sabor ácido antes do amadurecimento, como maçã e uva. Ocorre durante a fermentação de açúcar para álcool e é constituinte natural da manteiga, queijos, azeitonas e vegetais congelados. Surge também em vinhos e refrigerantes alcoólicos após exposição ao ar. Em algumas variedades de laranja pode chegar a 6000 ppm ou mg L-1 (AMERINE \& OUGH, 1987). 
Como aditivo é usado para realçar sabores cítricos em alimentos, contribuindo para fornecer características de aromas e sabores naturais de frutas e consta na lista do "The Handbook of Food Additives". Ainda como exemplos da aplicação na indústria de alimentos incluem a formulação de sorvetes, doces, chocolates, runs, vinhos, sobremesas de gelatina, etc., (GOOD YEAR, 1987). É também usado em formulação de perfumes, fabricação de borracha sintética, anilinas e outros produtos industriais não alimentícios. $\mathrm{O}$ acetaldeído tem sido encontrado em resíduos da refinação do petróleo, na degradação de hidrocarbonetos, lixos biológicos sólidos e em tratamentos de efluentes (IARC,1985).

\section{Formação, reações químicas e ocorrência em alimentos}

Algumas informações sobre a formação, reações químicas e ocorrência em alimentos e bebidas serão descritas de maneira a fornecer informações concretas a respeito da química do acetaldeído. A combustão de produtos de plásticos e espumas de poliuretano e policarbonato provoca a formação de acetaldeído. Isso pode ser explicado pela natureza química dos polímeros, que proporciona fracionamento das cadeias moleculares pelo calor, produzindo compostos e baixo peso molecular.

É considerado um subproduto da fermentação e um produto da combustão incompleta. A mobilidade do acetaldeído é limitada devido a sua alta reatividade. Entretanto, em função da alta pressão de vapor, dentre outras características, parte é transferida da água para o ar e para produtos no ambiente.Em artigo descrito por GROSJEAN \& WRIGHT (1983), os autores reportam que a reação do acetaldeído com radicais hidroxilas $(3 / 4 \mathrm{OH})$ pode remover do ar da cidade de Los Angeles, nos EUA, cerca de $50-300 \mathrm{t}$ de compostos carbonílicos, num período de 12 horas.

Níveis de acetaldeído de 0,1 mg L-1 foram detectados em água potável na Philadelphia e em Seattle nos EUA. Isso se deve aos resíduos de indústrias, como os já citados, em diferentes ramos da atividade industrial, conforme abordagem feita por Keith et al. (1976). Provavelmente a contaminação das fontes de água é devido à geração de acetaldeído pela queima de madeiras e à combustão inadequada e/ou não controlada de materiais plásticos e ainda, da fabricação de produtos químicos. Algumas propriedades físicas e químicas do acetaldeído são mostradas na Tabela 1 .

Tabela 1. Características físicas e químicas do acetaldeído.

\begin{tabular}{|c|c|c|}
\hline \multicolumn{2}{|l|}{ Cor } & Incolor \\
\hline \multicolumn{2}{|c|}{ Massa molecular relativa } & 44,1 \\
\hline \multicolumn{2}{|c|}{ Temperatura de evaporação (101,3 kPa) } & $20,2^{\circ} \mathrm{C}$ \\
\hline \multicolumn{2}{|c|}{ Temperatura de fusão } & $-123,5^{\circ} \mathrm{C}$ \\
\hline \multicolumn{2}{|c|}{ Temperatura de auto-ignição } & $185-193{ }^{\circ} \mathrm{C}$ \\
\hline \multirow[t]{3}{*}{ Pressão de vapor } & $-50{ }^{\circ} \mathrm{C}$ & $2,5 \mathrm{kPa}$ \\
\hline & $\mathbf{0}^{\circ} \mathbf{C}$ & 44,0 kPa \\
\hline & $20,16{ }^{\circ} \mathrm{C}$ & $101,3 \mathrm{kPa}$ \\
\hline \multicolumn{2}{|c|}{ Gravidade específica (20/4) } & 0.778 \\
\hline \multicolumn{2}{|c|}{ Densidade relativa do vapor } & 1.52 \\
\hline \multicolumn{2}{|c|}{ Índice de refração 20/D } & 1.33113 \\
\hline \multicolumn{2}{|c|}{ Constante de dissociação $\left(0^{\circ} \mathrm{C}, \mathrm{Ka}\right)$} & $0,7 \times 10^{-14}$ \\
\hline \multicolumn{2}{|c|}{ Solubilidade } & Miscível em água e solventes comuns \\
\hline
\end{tabular}

É comum encontrar níveis de acetaldeído em alimentos in natura e prontos para o consumo e em bebidas, particularmente em sucos de frutas e em refrigerantes alcoólicos.

Em vinagres, o valor máximo encontrado foi da ordem de $1060 \mathrm{mg} \mathrm{L}^{-1}$, reportado por MAARSE \&VISSCHER (1992). No caso particular dos vinagres, trata-se de produtos de origem fermentada, onde o acetaldeído é um componente presente nas frações 
nas frações intermediárias da fermentação, daí níveis maiores em produtos dessa natureza. $\mathrm{Da}$ mesma maneira, tais considerações são aplicadas às cervejas, vinhos e aguardentes de milho e de cana de açúcar.

Análises de 18 marcas de cervejas comercializadas na Inglaterra apresentaram níveis de acetaldeído variando de 2,6 a 13,5 mg
L-1, reportado por DELCOUR et al. (1982). Uma das principais utilizações do acetaldeído é na fabricação do ácido acético, mais importante ácido carboxílico que é preparado pela oxidação do acetaldeído através do ar. O acetaldeído é facilmente obtido através da hidratação do acetileno, como pode ser visto na Figura 4, descrita por MORRISON \& BOYD (1961).

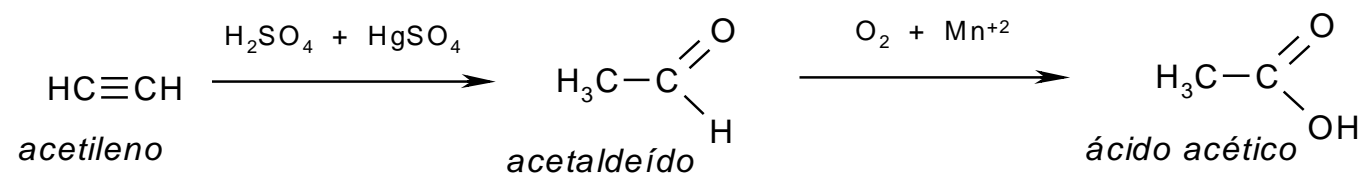

Figura 4. Obtenção do ácido acético através da hidratação do acetileno

Freqüentemente, o acetaldeído $\left(\mathrm{Pe} .20,2^{\circ} \mathrm{C}\right)$ é comercializado sob a forma do trímero paraldeído ( $\left.\mathrm{Pe} .125^{\circ} \mathrm{C}\right)$, obtido através do (Pe. $125^{\circ} \mathrm{C}$ ), obtido através do aquecimento deste, conforme é mostrado na Figura 5.

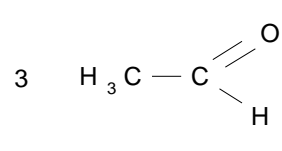

a c e tald e ído

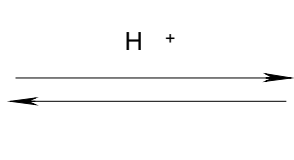

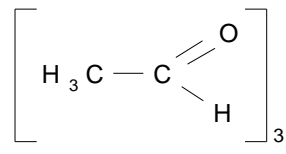

paralde ído

Figura 5. Obtenção do acetaldeído pelo aquecimento do paraldeído.

O acetaldeído é um composto altamente reativo que pode reagir com muitas outras moléculas de tamanhos maiores e menores, por adição, condensação ou polimerização. A principal fonte de exposição ao acetaldeído para a população é através do metabolismo do álcool. A ingestão de álcool através de bebidas alcoólicas provoca a formação de acetaldeído através da enzima álcool-desidrogenase
(ADH). O uso de cigarros também é uma fonte em potencial de exposição para as pessoas, pois o acetaldeído é um dos produtos da combustão do fumo (IARC, 1988).

Conforme descrito por BRUNE (1978), vários aldeídos podem sofrer reações de oxidação com substratos concorrentes através da enzima aldeído-desidrogenase do fígado, conforme mostrado na Figura 6.

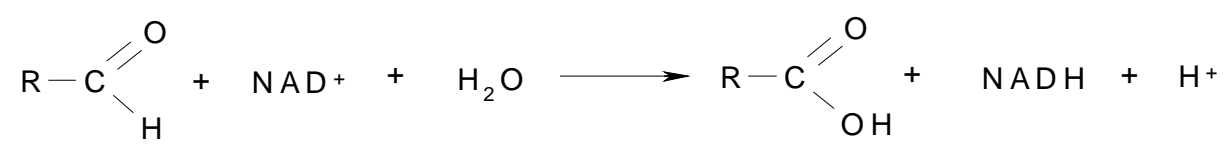

Figura 6. Reação de oxidação de aldeídos através da enzima aldeído-desidrogenase.

\section{Implicações em embalagens}

Os sabores e aromas de bebidas carbonatadas, não carbonatadas, águas minerais e vários outros produtos alimentícios podem ser alterados pela presença de acetaldeído proveniente da embalagem plástica de PET, seja em frascos, potes, garrafas ou garrafões. Atualmente, com a crescente utilização de embalagens de PET em diferentes segmentos de mercado, tais como águas minerais, bebidas isotônicas, chás, sucos de 
frutas, óleos comestíveis, molhos e temperos, alimentos complementares, geléias, doces em geral, produtos de higiene e limpeza e cosméticos em geral, o conhecimento em relação à presença do acetaldeído proveniente de embalagens torna-se cada vez mais importante. Conhecer o mecanismo pelo qual este composto interage com alimentos e bebidas afetando de certa maneira a estabilidade dos produtos é de fundamental importância para fabricantes de embalagens, alimentos e bebidas. Em algumas situações particulares o acetaldeído promove alterações de aroma e sabor pela simples mudança da característica natural de bebidas e também pela interação com componentes químicos presentes nas diferentes formulações de bebidas, afetando sensivelmente a estabilidade dos produtos acondicionados.

O acetaldeído em solução aquosa apresenta equilíbrio na forma hidratada $[\mathrm{H} 3 \mathrm{CCH}(\mathrm{OH}) 2]$, sendo que o grau de hidratação diminui com o aumento da temperatura. A respeito dessa afirmação, BELL \& CLUNIE (1952), relatam que a $0^{\circ} \mathrm{C}$ a fração de acetaldeído hidratada é 0,73 e a $25^{\circ} \mathrm{C}$ é de 0,59 . Nota-se que a temperatura exerce função importante nessa reação. Trata-se de um diálcool, composto facilmente dissociável, novamente formando acetaldeído, em temperaturas mais elevadas.

A Figura 7 mostra a reação de hidratação do acetaldeído na presença de água.

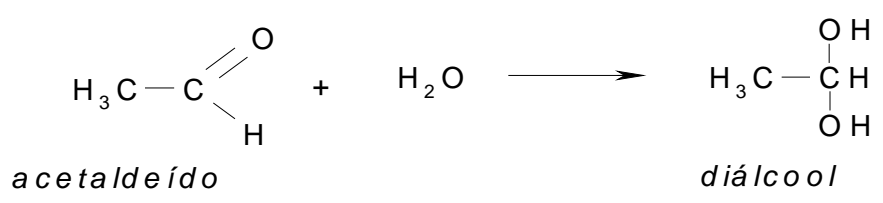

Figura 7. Reação de hidratação do acetaldeído na presença de água.

A solubilidade dos álcoois de baixo molecular em água deve-se ao fato de se formarem ligações de hidrogênio tanto entre uma molécula do álcool e uma da água, como entre duas moléculas de água ou entre duas moléculas do álcool. Dos materiais plásticos utilizados como material de embalagem os que mais merecem destaque quanto à presença de acetaldeído são os compostos da família dos poliésteres, que nesse caso incluem-se o PET e o poli (etileno naftalato) (PEN). O acetaldeído é formado durante a polimerização da resina de PET, caracteristicamente um polímero fabricado pelo processo de polimerização em fase líquida, seguido de polimerização em fase sólida para fornecer características apropriadas para a utilização na fabricação de embalagens sopradas para diversas aplicações. O acetaldeído aparece como um subproduto do termo degradação da resina de PET, através de grupos terminais hidroxi-etílicos e/ou via decomposição de ligações ésteres, de acordo com o mencionado por COFFMAN (1988), durante a fusão da resina a aproximadamente $270^{\circ} \mathrm{C}$ e devido ao atrito no interior do canhão da injetora associado com o tempo de exposição na temperatura de fusão. Basicamente, os dois mecanismos citados acima explicam a formação de acetaldeído pela termo degradação da resina de PET.

O acetaldeído formado no processo de injeção de pré-formas permanece retido na estrutura polimérica predominantemente amorfa e após o processo de sopro, difunde-se através da parede da embalagem a uma baixa taxa de difusão, manifestando-se nos produtos acondicionados, conforme abordado por DONG et al., (1980). As Figuras 8, 9, 10 e 11, mostram os mecanismos de formação do acetaldeído durante a polimerização da resina de PET e durante o processo de fabricação de pré-formas destinadas ao sopro de embalagens de PET, descritos por autores e explicadas pela natureza da estrutura química do polímero. A Figura 8 mostra o mecanismo de termo degradação dos grupos terminais hidroxietila nas moléculas de PET. 


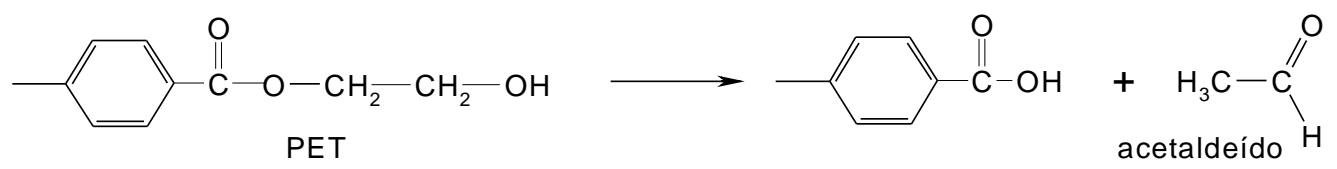

Figura 8. Reação de termo degradação de grupos terminais hidroxietila durante a fusão e transformação de resinas de PET em embalagens.

A Figura 9 mostra o mecanismo da formação de grupos éster-vinílico e di-éster de decomposição das ligações ésteres nas etilideno.

moléculas de PET, quando do aquecimento com

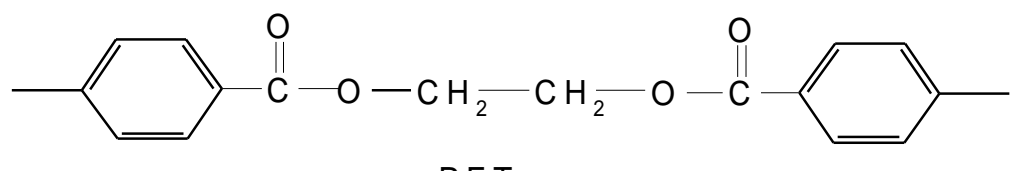

PET
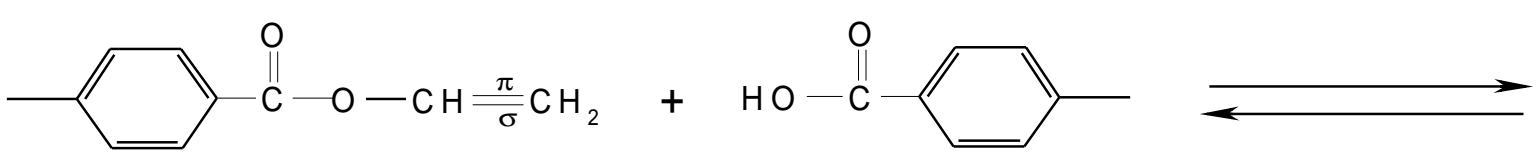

grupo éster-vinílico<smiles>Cc1ccc(C(=O)OC(C)OC(=O)c2ccc(C)cc2)cc1</smiles>

di-éster de etilideno

Figura 9. Reação de decomposição das ligações ésteres nas moléculas de PET durante a fusão e transformação de resinas em embalagens.

A Figura 10 mostra a formação de acetaldeído durante a fusão do PET. através dos grupos éster-vinílicos formados

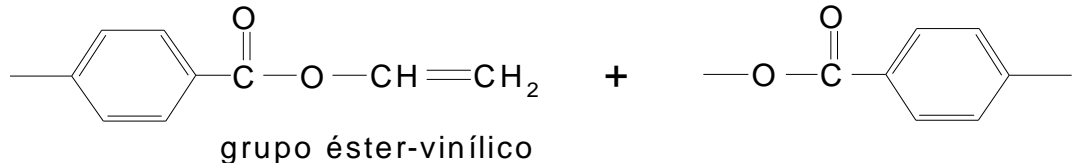

grupo éster-vinílico

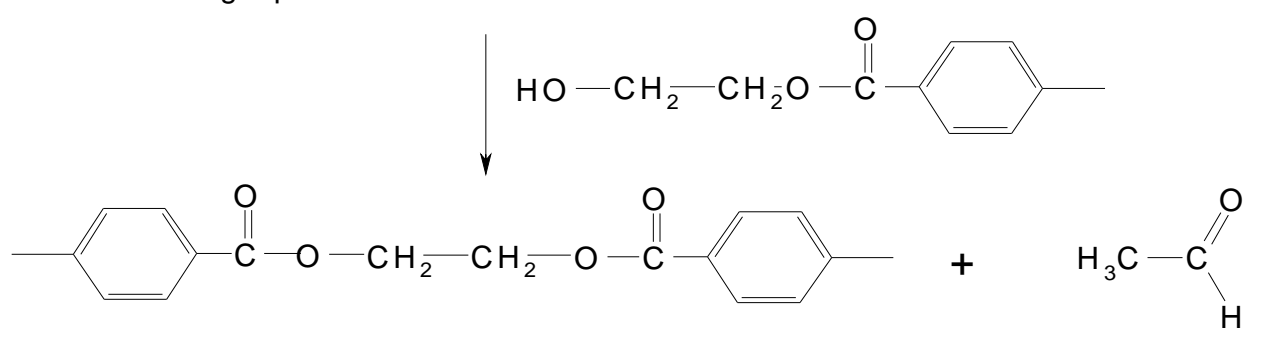

acetaldeído

Figura 10. Formação de acetaldeído através dos grupos éster-vinílicos formados durante a fusão e transformação do PET. 
A Figura 11 mostra o mecanismo de reação dos para formar o acetaldeído. grupos di-ésteres de etilideno que reagem

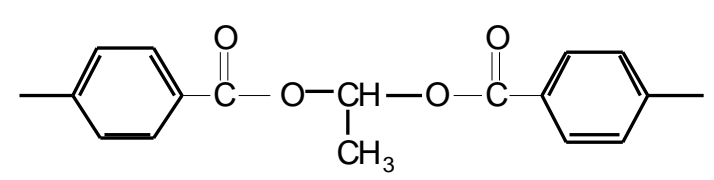

di-éster de etilideno

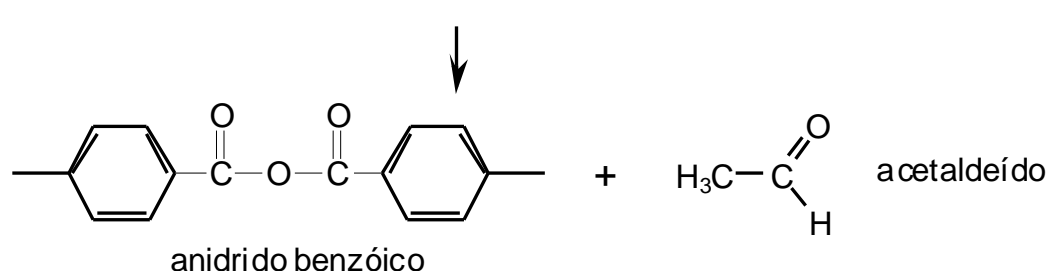

anidrido benzóico

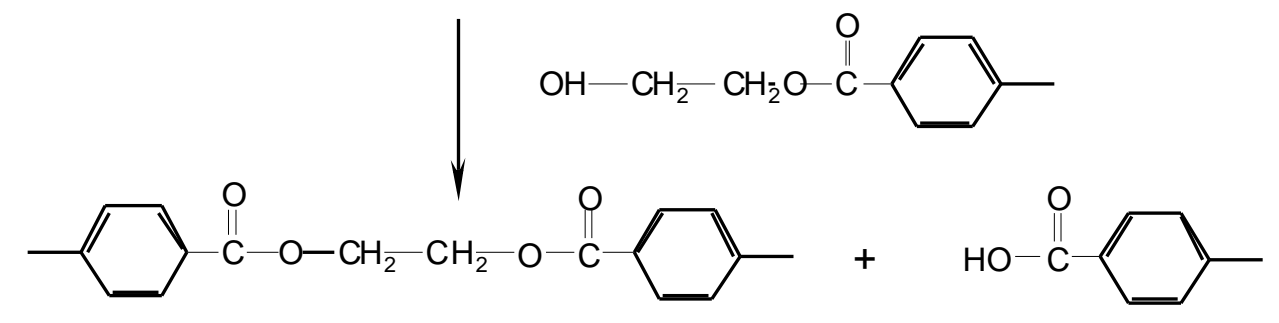

PET

Figura 11. Formação de acetaldeído através da reação de grupos di-ésteres de etilideno formados durante a fusão e transformação da resina de PET.

É possível produzir uma resina de PET para embalagens com baixos níveis residuais de acetaldeído, mas não é esse residual proveniente da polimerização nas fases líquida e sólida que provoca alterações nos produtos acondicionados, mas sim aquele gerado durante a fusão da resina para produzir as pré-formas ou embalagens finais, dependendo do processo a ser utilizado. Portanto, há que se controlar o processo de injeção no qual a resina fica exposta a elevadas temperaturas por tempo prolongado.

Além do fator tempo de permanência na temperatura de fusão, outros fatores são responsáveis pelos níveis residuais de acetaldeído encontrados em garrafas de PET, tais como: tipo e formulação da resina, tipo de equipamento, desenho da rosca da injetora e as condições de transformação.

\section{Condição de estocagem}

A influência das condições de estocagem na retenção e difusão de acetaldeído em embalagens sopradas de PET de $2000 \mathrm{~mL}$ foi estudada por ANJOS (1992) onde as amostras foram condicionadas logo após o sopro à temperatura ambiente, a $25,35,45$ e $55^{\circ} \mathrm{C}$, durante cinco dias. Concluiu-se que houve redução significativa dos níveis iniciais de acetaldeído em todas as temperaturas testadas. Quanto maior a temperatura de estocagem maior foi a taxa de redução. Após cinco dias as concentrações de acetaldeído foram de aproximadamente 0,$8 ; 0,3 ; 0,2$ e $0,1 \mathrm{mg} \mathrm{L}-1$ para as temperaturas de $25,35,45$ e $55^{\circ} \mathrm{C}$, respectivamente, sendo que os valores iniciais, ou seja, logo após o sopro foram 1,5; 1,3; 1,8 e $1,8 \mathrm{mg} \mathrm{L}-1$. Na estocagem à temperatura ambiente, inicialmente as amostras apresentaram níveis de aproximadamente 2,08 mg L- 1 e, após 5 dias de estocagem, os valores foram de aproximadamente de $0,34 \mathrm{mg} \mathrm{L}-1$. As análises foram conduzidas utilizando-se cromatografia gasosa e determinação no espaço interno das embalagens, segundo metodologia descrita em WYATT (1983).

Uma típica especificação de níveis residuais de acetaldeído em embalagens de PET para águas minerais é de $1,0 \mathrm{mg} \mathrm{L}-1$, determinada no espaço livre das mesmas por cromatografia gasosa, porém algumas 
empresas utilizam como especificação valores de 3 a 5 mg L-1 no espaço livre de garrafas descartáveis e retornáveis transparentes e cerca de 12 a $15 \mathrm{mg} \mathrm{L}-1$ para garrafas coloridas para refrigerantes carbonatados. Já para águas minerais os valores variam de 1,0 a $4,0 \mathrm{mg} \mathrm{L}-1$ no espaço livre de garrafas descartáveis. Para se obter valores nesses níveis nas garrafas torna-se necessário que as pré-formas apresentem níveis de acetaldeído menor que $25 \mathrm{mg} \mathrm{kg}-1$ (EASTMAN,1988). Valores residuais de acetaldeído determinados no espaço interno de garrafas originadas de pré-formas com valores também conhecidos são obtidos por algumas empresas com a finalidade de fixar parâmetros de equipamentos associados aos graus específicos de resinas. Esses valores podem ser utilizados com boa margem de segurança e garantir de certa forma a definição de um padrão de fabricação e de qualidade em fornecimento de pré-formas.

Conforme demonstrado por ANJOS et al., (1998), é possível reduzir o tempo de resposta das análises de determinação de acetaldeído no espaço interno de garrafas, utilizado pelas indústrias transformadoras e fornecedoras de embalagens. Nesse estudo o autor utilizou uma alternativa acelerada de teste com a finalidade de comparar com o procedimento padrão utilizado atualmente pelas empresas transformadoras. As condições estudadas foram de $50^{\circ} \mathrm{C} / 40 \mathrm{~min}$ contra $23^{\circ} \mathrm{C} / 24 \mathrm{~h}$ de estocagem para garrafas de $2000 \mathrm{~mL}$ recém sopradas e purgadas com nitrogênio, antes da análise do espaço interno por cromatografia gasosa. Os resultados da condição de $23^{\circ} \mathrm{C} / 24$ $\mathrm{h}$ foram de 1,05 mg L-1 (mínimo), 2,09 mg L-1 (médio) e 3,41 mg L-1 (máximo) em 200 amostras analisadas. $\mathrm{Na}$ condição de $50^{\circ} \mathrm{C} / 40$ min os resultados foram 1,53 mg L-1 (mínimo), 2,91 mg L-1 (médio) e 4,62 mg L-1 (máximo). No estudo, de fato, o autor demonstrou que a prática diária de determinação de acetaldeído nas indústrias poderá ser flexibilizada através das condições utilizadas, visando economia de tempo de resposta em fabricação, processo, estocagem, transporte e utilização de embalagens de PET.

DUARTE \& ANJOS (1999) determinaram o threshold absoluto de aroma e sabor para acetaldeído em diferentes marcas de águas minerais comercializadas no Brasil em embalagens de $\mathrm{PET}$, condicionadas a $12^{\circ} \mathrm{C}$. O objetivo da pesquisa foi a determinação mínima de acetaldeído em águas minerais que produz diferença sensorial detectável pelo consumidor.Os autores obtiveram valores entre 60 e $170 \mathrm{mg} \mathrm{L}-1$ de acetaldeído para sabor e 150 a $300 \mathrm{mg} \mathrm{L}-1$ para aroma nas amostras de água mineral natural a uma equipe treinada de provadores. Paráguas minerais carbonatadas os resultados obtidos foram de 150 a $450 \mathrm{mg}$ L-1 para sabor e de 200 a 1000 mg L-1 para aroma. Para cada amostra de água obteve-se um valor característico, podendo existir outros fatores que podem ter influenciado a estabilidade e a percepção de acetaldeído em águas minerais, tais como: oxigênio dissolvido, volume de $\mathrm{CO} 2$ composição química provável da água dentre outros.

Uma pesquisa sobre a influência da aplicação de microondas nos níveis residuais de acetaldeído em resina de PET destinada à fabricação de embalagens para bebidas foi conduzida por ANJOS et al., (1998) que compararam os resultados com aqueles obtidos com resina do mesmo lote, porém submetida ao processo de secagem convencional. O nível de acetaldeído determinado na resina virgem foi de aproximadamente $1,0 \mathrm{mg} \mathrm{kg}-1$ e após a secagem convencional os resultados médios encontrados para cada condição utilizada foram $165^{\circ} \mathrm{C} / 6 \mathrm{~h}-0,56 \mathrm{mg} / \mathrm{kg} ; 170^{\circ} \mathrm{C} / 6 \mathrm{~h}-0,50$ $\mathrm{mg} / \mathrm{kg} ; 175^{\circ} \mathrm{C} / 5 \mathrm{~h}-0,53 \mathrm{mg} / \mathrm{kg} ; 180^{\circ} \mathrm{C} / 5 \mathrm{~h}-0,52$ $\mathrm{mg} / \mathrm{kg}$; e $185^{\circ} \mathrm{C} / 5 \mathrm{~h}-0,52 \mathrm{mg} / \mathrm{kg}$. Após a aplicação da energia de microondas em diferentes condições, os resultados médios mais significativos de acetaldeído foram: 300 Watts/ $30 \mathrm{~min}-0,63 \mathrm{mg} / \mathrm{kg}$ e 50-100Watts/60min - 0,54. $\mathrm{mg} / \mathrm{kg}$. Nesse estudo, o autor utilizou um sistema onde a resina de PET foi alimentada em contra fluxo às microondas, por gravidade, com auxílio de uma rosca de teflon, mostrando que a aplicação da energia de microondas pode contribuir para a redução dos níveis residuais iniciais de acetaldeído na resina de PET em curto espaço de tempo, apesar de ser um polímero de baixa permissividade dielétrica, dificultando a absorção de energia pela estrutura molecular.

MORRISON \& BOYD (1961), mostram a reação do acetaldeído através da condensação aldólica sob a influência de ácidos ou álcalis em solução diluída. Os autores relatam que na reação de duas moléculas de acetaldeído ocorre formação de um composto químico denominado b-Hidroxi-butiraldeído ou 3-hidroxi-butanal, conforme é mostrado na Figura 12. 
<smiles>CC(=O)C=O</smiles>

Figura 12. Reação de combinação de duas moléculas de acetaldeído formando 3-hidroxi-butanal.

A diversidade de aplicações da resina de PET exige que graus diferenciados sejam desenvolvidos de maneira a favorecer o uso como embalagens e reduzir ao máximo a interação produto - embalagem, consequentemente aumentando a estabilidade dos produtos acondicionados.

As metodologias de determinação de acetaldeído em resinas, pré-formas, embalagens e em bebidas são conhecidas e bem utilizadas, porém de difícil manipulação pela complexidade em se manter uma estrutura equipada e em pleno funcionamento.

Os testes de determinação de aldeídos em bebidas podem ser através de reações de adição do grupo carbonilo $(\mathrm{C}=\mathrm{O})$ com reagentes nucleofílicos, especialmente com derivados do amoníaco. Um aldeído reagirá, por exemplo, com o 2,4 - dinitrofenil-hidrazina, com formação de um sólido insolúvel amarelo ou vermelho. $O$ reagente de Schiff é altamente sensível para os aldeídos. Os aldeídos reagem com o reagente de fuccina com formação de cor carmim característica (MORRISON \& BOYD,1961). Alguns autores determinaram a concentração de acetaldeído em águas minerais, seja proveniente da embalagem ou mesmo da adição e verificação do comportamento durante o tempo de estocagem. NIJSSEN et al., (1996), determinaram níveis de acetaldeído em águas minerais envasadas em garrafas de PET utilizando cromatografia gasosa com headspace. Em sua pesquisa, NIJSSEN pesquisou o threshold para aroma e a estabilidade de acetaldeído em água mineral.

GRAMICCIONI et al., (1986a) e (1986b) abordam aspectos tecnológicos e químicos da formação de acetaldeído e determinaram os níveis em águas minerais utilizando cromatografia gasosa acoplado a um headspace automático e detector de ionização de chama (FID). MONARCA et al., (1994), estudaram a migração de compostos voláteis e não volátei em águas minerais envasadas em garrafas de PET utilizando cromatografia gasosa com espectrofotômetro de massa. PORRETTA \& MINUTI (1995), determinaram a concentração de acetaldeído em água mineral e em bebidas não alcoólicas envasadas em embalagens de PET e os níveis de percepção sensorial. Nesse estudo o autor usou a metodologia de determinação por espectrofotometria, que se baseia na formação de cloridratos que sucessivamente são oxidados com aparecimento de cores que apresentam o máximo de absorção em comprimento de onda de $650 \mathrm{~nm}$. Tais reações são altamente específicas e sensíveis revelando concentrações de acetaldeído da ordem de mg $\mathrm{kg}-1$. As metodologias para a determinação de acetaldeído em embalagens de PET e PEN são através da medida no espaço interno das mesmas, nesse caso o resultado poderá ser expresso em mg L-1.

\section{Processo de injeção na geração de acetaldeído em embalagens}

Antes de iniciar a abordagem sobre a influência do processo de injeção na geração de acetaldeído em embalagens de PET é importante descrever uma das etapas mais significativas no processamento da resina de PET que é a secagem. Na forma sólida a resinade $P E T$ absorve umidade até um valor de equilíbrio com a umidade relativa local e em ambientes de elevadas umidades relativas pode chegar até $0,6 \%(p / p)$. Para se obter o máximo de desempenho da resina para utilização em embalagens, torna-se necessário que o valor de $0,6 \%(p / p)$ diminua para $0,005 \%(p / p)$ ou menos antes da resina entrar em fusão, porque irá hidrolisar o polímero, reduzindo o peso molecular e, conseqüentemente, as propriedades físicas, químicas e físico-químicas, conforme já discutido anteriormente (HASAN \& MUJUMDAR, 1987).

A hidrólise poderá iniciar-se durante a secagem e prolongar-se durante a fusão da resina na injeção, devido à umidade residual 
presente. A reação de hidrólise no PET iniciase a aproximadamente $150^{\circ} \mathrm{C}$ em taxas muito baixas, mas elevam-se com o aumento da temperatura, conforme está descrito em AKZO (1988). A taxa de hidrólise da resina de PET em função da temperatura é discutida por ICI (1988), em que descreve que à medida que a temperatura aumenta, a taxa de hidrólise aumenta, atingindo valores significativos acima de $220^{\circ} \mathrm{C}$. Essas informações são importantes, pois se procura trabalhar com resinas de baixas temperaturas de fusão a fim de retardar a degradação do polímero. Um dos artifícios utilizados pelas indústrias produtoras de resinas de PET é a de oferecer graus diferenciados ou resinas do tipo copolímero. O uso de dois monômeros diferentes para produzir copolímeros é uma alternativa para tornar mais flexível as condições de processamento da resina e ampliar a utilização. O termo copoliéster é usado para polímeros cuja síntese utilizou-se mais de um glicol e/ou mais de um ácido, como o etileno glicol, o dietileno glicol, o ciclohexano di-metanol e/ou os ácidos tereftálico e isoftálico. A estrutura molecular das cadeias dos copolímeros são mais irregulares quando comparadas com as estruturas dos homopolímeros e, portanto, apresentam menor tendência à cristalização. A adição de comonômeros também tem como efeito a redução do ponto de fusão das resinas em relação ao homopolímero. A redução do ponto de fusão permite a obtenção de graus de resinas com menor tendência à degradação térmica e geração de acetaldeído (EASTMAN, 1987).

No estado fundido, a reação do PET com a água é quantitativa e esta é a razão pela qual a resina deve ser cuidadosamente manuseada desde a secagem até o processo final, seguindo as orientações para cada tipo de resina e secador.

A Figura 13 mostra a reação de hidrólise da resina de PET submetida a elevadas temperaturas por tempo prolongado.
Na prática, cada $10^{\circ} \mathrm{C}$ de acréscimo na temperatura ótima de fusão da resina, ocorre aumento de duas vezes na formação de acetaldeído. É claro que para a completa fusão dos cristais da estrutura molecular do polímero, a fim de desfazer núcleos de cristalização ou cristalitos, deve-se elevar a temperatura, mas para manter reduzida a geração de acetaldeído é necessário manter a temperatura reduzida. Essas temperaturas de operação envolvem todas as zonas de fusão, ou seja, cilindro, canal de distribuição e bico de injeção. Nos canais de distribuição da resina no molde, o tempo, o resfriamento do molde e o tempo de ciclo de injeção podem afetar de certa maneira a geração de acetaldeído. O tempo de ciclo reduzido é muito importante, principalmente após a injeção, onde o tempo de resfriamento exerce função significativa na geração de acetaldeído. Quanto mais eficaz for o resfriamento menor será o ciclo e a geração de acetaldeído nas pré-formas.

\section{Considerações finais}

É importante que a umidade da resina seja determinada logo após o ciclo de secagem, antes de ser submetida à fusão, mesmo que todos os parâmetros do processo tenham sido devidamente controlados através dos instrumentos de leitura. A temperatura de secagem deve estar entre 170 e $180^{\circ} \mathrm{C}$, ideal $175^{\circ} \mathrm{C}$ e o tempo de secagem entre quatro e seis horas, dependendo da umidade inicial da resina. A temperatura do ar de regeneração das câmaras deve estar entre 190 e $200^{\circ} \mathrm{C}$ e no máximo $210^{\circ} \mathrm{C}$. O ponto de orvalho do ar desumidificado deve situar-se entre - 40 e $30^{\circ} \mathrm{C}$, preferencialmente $-40^{\circ} \mathrm{C}$ ou menor . $\mathrm{O}$ fluxo de ar deve ser da ordem de $4 \mathrm{~m} 3 \mathrm{~kg} \mathrm{~h}-1$ de resina. Essas condições são utilizadas com muita eficiência na secagem da resina de PET, no entanto, elas podem variar em função de diferentes fatores associados à resina e às<smiles>COCC(O)C1CCC(C(=O)CCC(C)(C)C)CC1</smiles>

Figura 13. Reação de hidrólise da resina de PET durante a secagem da resina por tempo prolongado em temperatura elevada. 
instalações de secagem, ou seja, ao tipo de secador.

A utilização de peneira molecular como material dessecante do ar e uma boa prática de limpeza do filtro de ar pode aumentar a vida útil do dessecante, e consequentemente, a qualidade da secagem, conforme descrito por CONAIR (1985). Deve-se levar em consideração e ser prática rotineira o controle efetivo do ponto de orvalho do ar de secagem pois de acordo com o descrito em KRUPP (1988), valores superiores a $-40^{\circ} \mathrm{C}$ afetam o valor da viscosidade intrínseca da resina. Segundo os autores, valor de $-30^{\circ} \mathrm{C}$ provocou redução na viscosidade intrínseca de $0,025 \mathrm{dL}$ g-1 e valor de $-20^{\circ} \mathrm{C}$ redução de $0,035 \mathrm{dL}$ g- 1 , aproximadamente.

Os materiais dessecantes utilizados na secagem de polímeros são analisados por HASAN \& MUJUMDAR (1987) quanto à eficiência, sendo que a sílica gel e a peneira molecular em forma de grânulos são as mais comumente utilizadas. A sílica gel remove mais umidade por peso, sendo mais apropriada para ar de secagem com elevadas umidades; quando se deseja ar muito seco é recomendada a utilização de peneira molecular.

Ressalta-se, ainda, como de importância a utilização de material reciclado ou o "scrap" de processo juntamente com resinas virgens. Essa prática poderá contribuir para a formação de acetaldeído pela redução da viscosidade intrínseca na mistura em fusão. $O$ excesso de pó fino gerado durante a moagem de material (pré-forma ou embalagens) rejeitado deverá ser separado, pois poderá aderir nas paredes do funil de secagem e com o passar do tempo cristalizar ou carbonizar e ao desprender-se ser conduzido ao processo de injeção, provocando alterações significativas nas zonas de temperaturas do processo.

Padrões de qualidade deverão ser estabelecidos entre usuário e transformador em função do uso final e de maneira a preservar identidade dos produtos acondicionados. Empresas de bebidas e alimentos deverão estabelecer os valores mínimos perceptíveis em seus produtos de maneira que o residual proveniente da embalagem não possa afetar significativamente a cor, sabor e aroma dos produtos.

\section{REFERÊNCIAS BIBLIOGRÁFICAS}

AMERINE, M.A.; OUGH, C. S. Methods for the analysis of musts and wine. New York: John Wiley and Sons, 1987. 341p.

ANJOS, C.A.R.; FARIA, J.A.F.; MARSAIOLI JR, A. Continuous microwave drying of poly (ethylene terephthalate) (PET). In: INTERNATIONAL CONGRESS OF FOOD ENGINEERING, 6. 1993, Tóquio. Proceedings... Tokio: Blackie Academic \& Professional, 1993. p. 796-798.

ANJOS, C.A. R.; FARIA, J.A.F.; MARSAIOLI JR, A. Prototype studies of a microwave rotary oven applied to the continuous drying of poly (ethylene terephthalate) (PET) resin. In: MICROWAVE POWER SYMPOSIUM, 29., 1994, Chicago. Proceedings... Chicago: IMPI, 1994. p. 214-217.

ANJOS, C.A.R. Influência das condições de estocagem na difusão de acetaldeído em embalagens de poli (etileno tereftalato) (PET) com revestimento de PVdC. Campinas, 1992. 96p. Tese (Mestrado em Tecnologia de Alimentos) - Faculdade de Engenharia de Alimentos, Universidade Estadual de Campinas.

ANJOS, C.A.R.; FARIA, J.A.F.; MARSAIOLI Jr., A. Influence of microwave energy on drying and on the physical and chemical properties of crystallized poly (ethylene terephthalate) (PET) resin. In: INTERNATIONAL CONFERENCE ON MICROWAVE CHEMISTRY, 1, 1998. Praga, Anais... Praga: República Tcheca 1998. p.53.

AKZO Plastics. Arnite for bottle. Why and how!. Technical information. Arnhem, NL.,1988. 44p.

BELL, R.P.; CLUNIE, J.C. The hydration of acetaldehyde in aqueous solutions. Transactions of Faraday Society, Piccadilly, RU, n.48, p. 439442. 1952. Royal Society of Chemistry

ASHLEY, R. J. Permeability in plastics packaging. In: COMYN, J. (Ed.) Polymers permeability. Barking: Elsevier, Applied Science, 1986. Chap. 7, p. 269-308.

BRANDT, W. W. Model calculation of the temperature dependence of small molecule diffusion in high polymers. Journal of Physical Chemistry. Washington, DC, n.63, p.1080-1084, 1959. 
BRUNE, W. Cálculo cinético em reações enzimáticas. Viçosa, MG: Imprensa Universitária, 1978. 83p.

CAIRNS, J.A.; OSWIN, C.R.; C.R.; PAINE, F.A. The theory of permeation. In: Packaging for climatic protection. London, 1974. Monograph: London: Newnes-Butterworth - Institute of Packaging . Chap. 3, p. 27-30.

CARTER, J.W.; BARRET, D.J. Comparative study for fixed bed adsorption of water vapor by activated alumina, silica gel and molecular sieve adsorbents. Transactions of the Institute of Chemical Engineers, London, RU, n.51, p. 7581, 1973.

CASTLE, L.; MAYO A. CREWS, C.R.; GILBERT, J. Migration of permeation. In: Packaging for climatic protection. London, 1974. Monograph: London: Newnes-Butterworth - Institute of Packaging Chap. 2, p. 4-22.

COFFMAN, P. Polyester polymer. São Paulo. $\mathrm{ICI}, 1988.37 p$. Boletim Técnico.

CONAIR, INC. Dehumidifying dryers and pre heaters for plastic processors. Technical Report. Form n. 9300 CL 1/85 Washington, DC: Franklin, 1985. $14 p$.

DELCOUR, J.A.; CAERS, J.M.; DONDEYNE, P.; DELVAUX, F.; ROBBERECHTS, E. An enzymatic assay for the determination acetaldehyde in beers. Journal of the Institute of Brewing, London, UK, n.88, p.384-386. 1982.

DONG, M.; DIEDWARDO, A.H.; ZITOMER, F. Determination of residual acetaldehyde in poly (ethylene terephthalate) bottles, preforms and resins by automated headspace gas chromatography. Journal of Chromatography Science, Niles, IL, v. 18, n. 5, p. 242-246, 1980.

DUARTE, G.M.B.; ANJOS, C.A.R.; SILVA, M. A. A. P. Determinação do threshold absoluto de acetaldeído em águas minerais. In: SIOMPÓSIO LATINO AMERICANO DE CIÊNCIA DE ALIMENTOS, 3., 1999, Campinas. Resumos. Campinas: UNICAMP, 1999. p. 147-148.

EASTMAN CHEMICAL COMPANY. Polyester plastics for packaging. Kingsport: Technical Report Form 70A, 1987. 18p.
EASTMAN CHEMICAL COMPANY. Polyester plastics for packaging. Model for the diffusion of acetaldehyde in beverage bottles molded from Kodapak. Kingsport: Technical Report Form, 1988. 18p.

ENCON, INC. ENCON'S wall variation gages laboratory blow moulding equipment short-term acetaldehyde testing and automatic testing equipment. Kingsport: Technical Report Form, 1989. 26p.

FUKUDA, M.; KAWAY, H.; YAGI, N.; KIMURA, O.; OHTA T. FTi.r. Study on the nature of water sorbet in poly (ethylene terephthalate) film. Polymer, Elsevier, OX, v. 31, n.2, p.275-302, 1990.

GILBERT, S.G.; HUANG-LAI, G.R.; LAI, C.C. Environmental and material composition effects on film permeability as related to meat packaging. American Meat Science Association Savoy, IL, n.36 p.47-54, 1983.

GOOD YEAR. Cleartuf. PET packaging resins. Virginia: Technical Report Form, 1987. 16p.

GRAMICCIONI, L. Acetaldehyde migration from PET containers: technological and chemical aspects. Industrie delle Bevande, Pinerolo, TO, v.15 n.81 p. 1 - 4, 1986.

GRAMICCIONI, L.; MILANA, M.R.; Di MARZIO, S. G.S. Determination of traces of acetaldehyde in aqueous matrix: a rapid headspace method. Chromatographia, USA, vol.21, n.1, 1986.

GRAMICCIONI, L.; MILANA, M.R.; Di MARZIO, S.; LORUSSO, S. La migrazione dell'acetaldehyde da contenitori in polietilentereftalato (PET): aspetti tecnologici e chimici. Industrie delle Bevande, Pinerolo, TO, p.1-4. feb., 1986.

GROSJEAN, D.; WRIGHT, B. Carbonyls in urban fog, ice fog, cloud water and rainwater. Atmospheric environment, Elsevier, v.17 n.10 p. 2093-2096. 1983.

HAGEMEYER, H.J. Acetaldehyde. In:

GRAYSON, M. Ed. Kirk-Othmer encyclopedia of chemical technology, 3. ed. New York: John Wiley and Sons, vol. 1, p. 97-112, 1978. 
HASAN, M.; MUJUNDAR, A.S. Drying of polymers. In: MUJUNDAR, A.S. (Ed.) Handbook of industrial drying. New York: Marcel Dekker, 1987. Chap. 25, p.757-788.

HAWTHORNE, J. M. \& HEFFELFINGER, C.F. Plastics, resins, rubbers and fiber. In: Encyclopedia of polymer science and technology. USA: Interscience, 1969. v. 11, p. 42-61.

IMPERIAL Chemical Industries - ICI. Poly (ethylene terephthalate). Melinar TM: technical aspects of injection moulding. Middlesbrough: Technical Report Form, 1988. 36 p.

INTERNATIONAL Agency for Research on Cancer - IARC. Man-made fibers and radon. In: Monographs on the evaluation of carcinogenic risk of chemicals to humans. Lyon, France: International Agency for Research on Cancer. 1988. v. $43,300 \mathrm{p}$.

INTERNATIONAL Agency for Research on Cancer - IARC: Allyl compounds, aldehydes, epoxides and peroxides In: Monographs on the evaluation of carcinogenic risk of chemicals to humans. Lyon, France: International Agency for Research on Cancer, 1985. v.36, p. 101

INTER-TECH LTD. The Injection moulding machine: extruder and screw design. Atlanta, GA: Technical Report Form, 1985. 17 p.

INTER-TECH LTD. PET melting point and glass transition temperature. Atlanta, GA: Technical Report Form, 1987. p. 5-7

KAREL, M. Packaging protection for oxygensensitive glycol from PET bottles into 3\% aceticacid. Journal Association Official Analytical Chemistry, Washington, DC, v.63, p. 168-172, 1980.

KEITH, L.H.; GARRISON, A.W.; ALLEN, F.R.; CARTER, M.H.; FLOYD, T.L.; POPE, J.D.; THRUSTON, A.D. Identification of organic compounds in drinking water from thirteen U.S. cities. In: Identification and analysis of organic pollutants in water. Ann Arbor, MI: Ann Arbor Press, 1976. p. 329-373
KISHIMOTO, A. FUJITA, H. Successive differential absorptions of vapors by glassy polymers. Journal of Physical Chemistry, Washington, DC, v. 64 p. 594-598, 1960.

KRUPP CORPOPLAST. Minimal acetaldehyde content in PET bottles for up market mineral water. PET Pointer, v.1, n. 5, p. 8, 1988.

MAARSE, H.; VISSCHER, C.A. Volatile compounds in food: qualitative and quantitative data. Supplement 3 and cumulative index. Zeist, Central Institute for Nutrition and Food Research. TNO, Biotechnology and Chemistry Institute, p. 33-41. 1992.

MONARCA, S.; De FUSCO, R.; BISCARDI, D.; De FEO, V.; PASQUINI, R.; FATIGONE, C.; MORETTI, M.; ZANARDINI, A. Studies of migration of potentially genotoxi compounds into water stored in pet bottles. Food and Chemical. Toxicology, Elsevier, vol. 32, n.9, p. 783-788, 1994.

MORRISON, R. T.; BOYD, R. N. Química orgânica. São Paulo: Cardoso, 1961. 1061p.

NIJSSEN, B.; KAMPERMAN, T.; JETTEN, J. Acetaldehyde in mineral water stored in poly(ethylene terephthalate) (PET) bottles: odour threshold and quantification. Packaging Technology and Science, NY, n. 9, p.175-185, 1996.

PACE, R. J. \& DATYNER, A. Statistical mechanical model for diffusion of simple penetrants in polymers. II: applications non vinyl polymers. Journal of Polymer Science. Hoboken, NJ, $\quad$ n. 17: 453-464, 1979.

PORRETTA, S.; MINUTI, E. Determinazione dell'acetaldehyde in acqua minerale $e$ in bevande analcoliche commerciali confezionate in PET e della soglia di percezione sensoriale. Industria delle Conserve Alimentari - SSICA, Parma, IT, n.70, 1995.

SHAH, R.M. \& ARORA, P. K. Drying characteristics of polyester chips, product quality and state of the art drying system In: INTERNATIONAL DRYING SYMPOSIUM, 10, 1996, Kraków. Proceedings... Montreal: McGill University, 1996. v. B, p.1351-1360. 
TAYLOR, E. The dual ovenable, frozen food tray market: the critical issues surrounding the processing and use of PET. In: CO-EX Europe in 86. INTERNATIONAL COEXTRUSION CONFERENCE. Proceedings... Cologne, 1986. p.299-318.

TREYBAL, R. E. Mass-transfer operations. 30 ed. Tokio: McGraw-Hill, 1980. Chap. 4, p.89101.

WHITEHEAD, B.D. The crystallization and drying of poly (ethylene terephthalate) (PET). Industrial and Engineering Chemistry Process Design and Development, Washington, DC, v. 16, n. 3, p. 341-346. 1977.

WYATT, D.M. Semi-automation of headspace as applied to determination of acetaldehyde in PET bottles. Journal of Chromatography Science, Niles, IL, v. 21, n. 11, p. 509-511, 1983. 